\title{
Effect of optic disc size or age on evaluation of optic disc variables
}

\author{
Changwon Kee, Hyungjin Koo, Yonghoon Ji, Seonwoo Kim
}

\begin{abstract}
Aims/background-It has been reported that the number of optic nerve fibres decrease with age, and the cup/disc (C/D) ratio increases as the optic disc size increases. Consequently, the normal value of the optic disc variables measured by an optic disc analyser may change according to the optic disc size or age. The effect of individual variations in optic disc size or age on interpretation of optic disc variables was investigated.
\end{abstract}

Methods-Topographic optic disc variables of 104 normal Asian adults of both sexes aged 40 to 68 were measured using a confocal scanning laser ophthalmoscope (TopSS, Laser Diagnostic Technologies, Inc). Fourteen variables were evaluated according to the optic disc size or age. Statistical analysis was done by regression analysis.

Results-With an increase in optic disc size, the increase in cup shape, effective area, 1/2 depth area, C/D ratio, neuroretinal rim area, volume above, volume below, and 1/2 depth volume were statistically significant $(p<0.05)$. However, contour variation, mean contour depth, average depth, maximum depth, average slope, and maximum slope were not affected $(p>0.1)$. Age did not have any significant influence on optic disc variables (p>0.1).

Conclusion-Optic disc size, but not age, should be considered in the interpretation of optic disc variables.

(Br f Ophthalmol 1997;81:1046-1049)

Optic disc examination, which is one of the important examinations in the diagnosis of glaucoma, has been performed by ophthalmoscope, aspherical lens, or photograph. ${ }^{1-3} \mathrm{Re}-$ cently, with the development of the confocal scanning laser ophthalmoscope, sophisticated three dimensional analysis of the optic disc became available. ${ }^{4}$ However, it is only useful for detecting optic disc changes in the progression of glaucoma, and needs more studies if it is to be used in the diagnosis of glaucoma, because the mean optic disc variable values among normal subjects and glaucoma patients overlap considerably.

Normal values for threshold perimetric analysis are dependent on patient age and retinal location, ${ }^{6-8}$ therefore it could be postulated that the optic disc variables should also be evaluated according to the optic disc size or age.

It has been reported that as the optic disc size increases, the neuroretinal rim area also increases. ${ }^{9}{ }^{10}$ Therefore, the normal values of other optic disc variables measured by optic disc analyser may change depending on optic disc size. It has also been reported that the number of optic nerve fibres decrease with age, therefore we attempted to observe the change in optic disc variables with increase in age using subjects with similar optic disc sizes to eliminate the error by the individual variation of optic disc size.

\section{Subjects and methods}

One hundred and four normal Asian adults of both sexes visiting Samsung Medical Center for routine physical examination were enrolled into this study. These individuals had no history of ocular disease.

Baseline images were created by the average of three images measured by confocal scanning laser ophthalmoscope (TopSS, Laser Diagnostic Technologies Inc). This instrument projects a near infrared diode laser beam (wavelength $780 \mathrm{~nm}$ ) on the retina and optic disc, and records the reflected light. From the measured reflectivity intensities it calculates topographic maps, and produces three dimensional images of the optic disc by multiple optical sectioning of the object; a series of two dimensional transverse optical section images parallel to the object's surface is recorded and the focal plane is moved in consecutive steps. Such a tomographic series forms a three dimensional image of the object, which consists of 32 image planes of $256 \times 256$ pixels each. After each acquisition, the instrument verifies that blinking, exposure, range of depth, offset, and saturation were correct. Three images per eye centred on the optic disc were obtained in a single session, and the three depth values obtained for each pixel were averaged to produce a baseline topographic image. By determining the margin of the optic disc from the obtained topographic image, 14 optic disc variables are automatically measured. They are: contour variation, the difference between the maximum height and the minimum height values along the defined margin of the optic disc; mean contour depth, the average of all the height values along the defined margin of the optic disc; cup shape, the position of the centre of gravity of the cup; effective area, the area of optic cup; 1/2 depth area, the area of all points half way between the cup margin and the bottom; cup/disc ratio, 
Table 1 Values of the optic disc variables in 104 normal subjects

\begin{tabular}{|c|c|c|}
\hline Variable (unit) & Mean & $S D$ \\
\hline Contour variation $(\mathrm{mm})$ & 0.370 & 0.095 \\
\hline Mean contour depth (mm) & -0.009 & 0.078 \\
\hline Cup shape & -0.058 & 0.031 \\
\hline Effective area $\left(\mathrm{mm}^{2}\right)$ & 1.101 & 0.407 \\
\hline $1 / 2$ depth area $\left(\mathrm{mm}^{2}\right)$ & 0.436 & 0.232 \\
\hline $\mathrm{C} / \mathrm{D}$ ratio ${ }^{\star}$ & 0.433 & 0.116 \\
\hline NRRA $f\left(\mathrm{~mm}^{2}\right)$ & 1.401 & 0.355 \\
\hline Volume above $\left(\mathrm{mm}^{3}\right)$ & 0.227 & 0.081 \\
\hline Volume below $\left(\mathrm{mm}^{3}\right)$ & -0.262 & 0.145 \\
\hline $1 / 2$ depth volume $\left(\mathrm{mm}^{3}\right)$ & -0.053 & 0.037 \\
\hline Average depth $(\mathrm{mm})$ & -0.220 & 0.075 \\
\hline Maximum depth (mm) & -0.536 & 0.185 \\
\hline Average slope (degree) & 31.244 & 6.016 \\
\hline Maximum slope (degree) & 77.455 & 4.496 \\
\hline
\end{tabular}

${ }^{\star} \mathrm{C} / \mathrm{D}=\mathrm{cup} / \mathrm{disc} ;+\mathrm{NRRA}=$ neuroretinal rim area.

calculated by dividing the effective area by the total optic disc area; neuroretinal rim area, the difference between the total optic disc area and the effective area; volume above, the volume of all tissue or structure within the neuroretinal rim area; volume below, the volume of the cup below the effective area; $1 / 2$ depth volume, the volume of the cup below the $1 / 2$ depth area; average depth, the average of the differences in height values at the reference plane and the corresponding height values within the cup; maximum depth, average of the lowest $5 \%$ of all the height values; average slope, the average of the slope values for all the pixels within the optic disc; and maximum slope, the maximum slope value for all the pixels within the optic disc. To determine the volumetric reproducibility, a total of three independent sets of images of optic disc were obtained for each 10 individuals. From this the mean of the average standard deviation and the coefficient of variation were calculated.

For evaluating the effect of individual variation in the optic disc size or age on optic disc variables, one eye of each subject was chosen randomly and used for analysis. Only those images having less than 4 degrees contour tilt were included to exclude tilted high myopic discs. The spherical equivalent of refractive error of the subjects included was less than -3 dioptres, and intraocular pressure measured by non-contact tonometer (Topcon CT-50) was less than $21 \mathrm{~mm} \mathrm{Hg}$.

The cup margin was defined at $100 \mu \mathrm{m}$ below the retinal reference plane as recommended by the instrument manufacturer. Scan

Table 2 Volumetric reproducibility of optic disc variables measured by TopSS

\begin{tabular}{lll}
\hline Variable & $S D$ & $C V^{\star}(\%)$ \\
\hline Contour variation $(\mathrm{mm})$ & 0.039 & 8.3 \\
Mean contour depth $(\mathrm{mm})$ & 0.012 & 7.3 \\
Cup shape & 0.028 & 7.9 \\
Effective area $\left(\mathrm{mm}^{2}\right)$ & 0.047 & 3.9 \\
1/2 depth area $\left(\mathrm{mm}^{2}\right)$ & 0.062 & 6.8 \\
C/D ratio† & 0.019 & 4.0 \\
NRRA $\ddagger\left(\mathrm{mm}^{2}\right)$ & 0.057 & 4.7 \\
Volume above $\left(\mathrm{mm}^{3}\right)$ & 0.017 & 8.9 \\
Volume below $\left(\mathrm{mm}^{3}\right)$ & 0.023 & 4.0 \\
1/2 depth volume (mm $\left.{ }^{3}\right)$ & 0.018 & 8.3 \\
Average depth $\left(\mathrm{mm}^{2}\right)$ & 0.019 & 4.3 \\
Maximum depth (mm) & 0.049 & 5.0 \\
Average slope (degree) & 1.225 & 2.9 \\
Maximum slope (degree) & 0.829 & 1.4 \\
\hline
\end{tabular}

${ }^{\star} \mathrm{CV}=$ coefficient of variation; $+\mathrm{C} / \mathrm{D}=\mathrm{cup} / \mathrm{disc} ; \ddagger \mathrm{NRRA}=$ neuroretinal rim area. angle was selected at $10^{\circ}$, and scan depth and scan offset were adjusted at $3 \mathrm{~mm}$ and 3 , respectively. The optic disc margin was defined by changing the shape of ellipse and fitting the best ellipse around the scleral ring.

Fourteen optic disc variables were evaluated according to the optic disc size or age. To determine the effect of optic disc size on the optic disc variables, we observed the change of each optic disc variable as the optic disc size increased in the 104 subjects. To evaluate the effect of age on optic disc variables, we analysed the variability of each optic disc variable as age increased in the 77 subjects with optic disc sizes equal to or greater than $2 \mathrm{~mm}^{2}$ and equal to or less than $3 \mathrm{~mm}^{2}$.

Statistical analysis was done by regression analysis.

\section{Results}

The mean (SD) optic disc size of 104 subjects was $2.502(0.524) \mathrm{mm}^{2}$ and ranged from 1.417 $\mathrm{mm}^{2}$ to $4.024 \mathrm{~mm}^{2}$; other values of optic disc variables are shown in Table 1.

The volumetric reproducibility which was expressed by mean standard deviation and coefficient of variation of the three measurements that made up a baseline image in each of 10 subjects ranged from 0.012 to 1.125 , and from $1.4 \%$ to $8.9 \%$, respectively (Table 2 ).

With increase in optic disc size the increases in cup shape, effective area, 1/2 depth area, $\mathrm{C} / \mathrm{D}$ ratio, neuroretinal rim area, volume above, volume below, and 1/2 depth volume were statistically significant. However, contour variation, mean contour depth, average depth, maximum depth, average slope, and maximum slope were not affected (Table 3 ).

The mean (SD) age of 77 subjects used for analysing the effect of age on optic disc variables was 52.4 (6.8) years and ranged from 40 to 68 years. Age did not seem to have any statistically significant influence on optic disc variables (Table 4).

\section{Discussion}

Since optic disc change precedes visual field defect in glaucoma patients, examination of the optic disc is thought to be more valuable than the visual field test for early detection of glaucoma. ${ }^{11-13}$ The interobserver variation is smaller in determining the margin of optic disc than that of cupping, ${ }^{14}$ therefore reproducibility and accuracy in evaluating the optic disc with an optic disc analyser, which measures the variables automatically only by determination of the optic disc margin, could be much higher than with an ophthalmoscope or a photograph where the examiner needs to decide on all of the variable data himself. In addition, the optic disc analyser could perform the volumetric evaluation of the optic disc.

The reproducibility of measurements of the optic nerve head with the TopSS was excellent and comparable with other types of optic disc analyser such as the Heidelberg retina tomograph. The mean coefficient of variation for multiple examinations in normal subjects with 
Table 3 Effect of disc size on optic disc variables

\begin{tabular}{lllr}
\hline Variable & Equation & p Value & \multicolumn{1}{c}{$R^{\star}$} \\
\hline Contour variation & $\mathrm{y}=0.348+0.009 \mathrm{x}$ & 0.630 & 0.045 \\
Mean contour depth & $\mathrm{y}=0.033-0.017 \mathrm{x}$ & 0.251 & -0.114 \\
Cup shape & $\mathrm{y}=-0.019-0.015 \mathrm{x}$ & 0.008 & -0.259 \\
Effective area & $\mathrm{y}=-0.329+0.572 \mathrm{x}$ & 0.001 & 0.736 \\
$1 / 2$ depth area & $\mathrm{y}=-0.232+0.267 \mathrm{x}$ & 0.001 & 0.603 \\
C/D ratio $\dagger$ & $\mathrm{y}=0.288-0.058 \mathrm{x}$ & 0.007 & -0.263 \\
NRRA & $\mathrm{y}=0.330+0.428 \mathrm{x}$ & 0.001 & 0.632 \\
Volume above & $\mathrm{y}=0.024+0.081 \mathrm{x}$ & 0.001 & 0.525 \\
Volume below & $\mathrm{y}=0.049-0124 \mathrm{x}$ & 0.001 & -0.448 \\
1/2 depth volume & $\mathrm{y}=0.014-0.027 \mathrm{x}$ & 0.001 & -0.381 \\
Average depth & $\mathrm{y}=-0.202-0.007 \mathrm{x}$ & 0.618 & -0.045 \\
Maximum depth & $\mathrm{y}=-0.575+0.016 \mathrm{x}$ & 0.657 & 0.045 \\
Average slope & $\mathrm{y}=27.073+1.667 \mathrm{x}$ & 0.141 & 0.145 \\
Maximum slope & $\mathrm{y}=77.431+0.010 \mathrm{x}$ & 0.991 & 0.000 \\
\hline
\end{tabular}

${ }^{\star} \mathrm{R}=$ correlation coefficient $+\mathrm{C} / \mathrm{D}=$ cup/disc; $¥ \mathrm{NRRA}=$ neuroretinal rim area.

Table 4 Effect of age on optic disc variables

\begin{tabular}{lllr}
\hline Variable & Equation & $p$ Value & \multicolumn{1}{c}{$R^{\star}$} \\
\hline Contour variation & $\mathrm{y}=0.265+0.002 \mathrm{x}$ & 0.134 & 0.173 \\
Mean contour depth & $\mathrm{y}=-0.112+0.002 \mathrm{x}$ & 0.220 & 0.141 \\
Cup shape & $\mathrm{y}=-0.079+0.001 \mathrm{x}$ & 0.405 & 0.095 \\
Effective area & $\mathrm{y}=1.296-0.005 \mathrm{x}$ & 0.413 & -0.095 \\
1/2 depth area & $\mathrm{y}=0.688-0.005 \mathrm{x}$ & 0.131 & -0.173 \\
C/D ratio & $\mathrm{y}=0.536-0.002 \mathrm{x}$ & 0.332 & -0.114 \\
NRRA & $\mathrm{y}=0.988+0.009 \mathrm{x}$ & 0.150 & 0.167 \\
Volume above & $\mathrm{y}=0.152+0.001 \mathrm{x}$ & 0.399 & 0.118 \\
Volume below & $\mathrm{y}=-0.397+0.002 \mathrm{x}$ & 0.342 & 0.109 \\
1/2 depth volume & $\mathrm{y}=-0.100+0.001 \mathrm{x}$ & 0.154 & 0.164 \\
Average depth & $\mathrm{y}=-0.265+0.001 \mathrm{x}$ & 0.627 & 0.055 \\
Maximum depth & $\mathrm{y}=-0.231-0.006 \mathrm{x}$ & 0.076 & -0.205 \\
Average slope & $\mathrm{y}=30.113+0.034 \mathrm{x}$ & 0.739 & 0.045 \\
Maximum slope & $\mathrm{y}=72.987+0.097 \mathrm{x}$ & 0.191 & 0.152 \\
\hline
\end{tabular}

${ }^{\star} \mathrm{R}=$ correlation coefficient $; \mathrm{C} / \mathrm{D}=\mathrm{cup} / \mathrm{disc} ; \ddagger \mathrm{NRRA}=$ neuroretinal rim area.

the Heidelberg retina tomograph has been reported as $4.8 \%$ for neuroretinal rim area, $3.4 \%$ for cup area, $4.6 \%$ for cup volume, and $4.0 \%$ for maximal depth. ${ }^{15}$ The corresponding values using the TopSS were $4.7 \%, 3.9 \%$, $4.0 \%$, and $5.0 \%$, respectively.

The optic disc size varies individually, ${ }^{16}{ }^{17}$ and as the optic disc size increases the neuroretinal rim area also increases. ${ }^{9} 10$ Therefore, it could be hypothesised that the optic disc size could influence other variables measured by an optic disc analyser.

It has been reported that the neuroretinal rim area decreases with age, ${ }^{18-22}$ but other studies show that there is no change in neuroretinal rim area with age. ${ }^{23}{ }^{24}$ The reason for this contradiction in results is that data were analysed irrespective of the optic disc size. If most of the subjects included in the old age group had large optic disc sizes, the neuroretinal rim area would not be decreased, even though the neuroretinal rim area may decrease with age.

The best way to check the variation in optic disc variables with age is to follow up some volunteers over a period of time. However, it is impossible in this kind of cross sectional study, and if we perform a longitudinal study, it needs a long follow up time. Therefore, in this study, we evaluated the influence of age on optic disc variables using the subjects with similar optic disc sizes to minimise errors which could be derived from the individual optic disc size variations.

Optic disc variables related to area or volume were influenced by optic disc size; however, those related to depth were not affected by optic disc size. It could be said that as optic disc size increases, the cup is widened but not deepened. Hence, the depth change of cup could also be a good clue in the detection of glaucomatous optic disc.

Our results indicate that age is not a necessary factor in the evaluation of optic disc variables. In other words, the cup is not enlarged or deepened with age. It correlates well with the studies that there is no statistically significant decrease in the number of nerve fibres with age. ${ }^{25-27}$ Other studies have shown that nerve fibres decrease by 4000 to 12000 fibres per year. ${ }^{28-30}$ Even though there may be loss of nerve fibres, they may be replaced by glial or other tissue, and thus not detected by topographic evaluation.

In this study we included a subject with less than 4 degrees of contour tilt because we used only the reference plane in the determination of the cup; evaluation of the tilted disc in the myopic eye using the reference cup is recommended rather than using the reference plane because in these tilted discs the plane will be higher than the lower side of the optic nerve head and the resulting volumetrics will be higher than the actual values. Further study is necessary to determine factors affecting the optic disc variables in myopic tilted discs.

In conclusion, optic disc size but not age should be considered in the determination of normal values of optic disc variables. If normal values of each optic disc variable were determined using a large number of samples, the optic disc analyser could be useful not only for early detection of progression of glaucoma but also for early diagnosis of glaucoma.

This study was supported by grant SMC96 from the Samsung Medical Center, Seoul, Korea.

1 Spenser AF, Vernon SA. Optic disc measurement: a comparison of indirect ophthalmoscopic methods. $\mathrm{Br} \mathcal{F}$ Ophthalmol 1995;79:910-5.

2 Pashby RC, MacDonald RD. Photographic assessment of the optic disc. Can f Ophthalmol 1975;10:286-9.

3 Erkkila H, Laatikainen L. Characteristics of optic disc in Erkkila H, Laatikainen L. Characteristics of optic disc in 4 Chihara E, Takahashi F, Chihara K. Assessment of optic disc topography with scanning laser ophthalmoscope. Graefes Arch Clin Exp Ophthalmol 1993;231:1-6.

5 Woon WH, Fitzke FW, Bird AC, Marshall J. Confocal imaging of the fundus using a scanning laser ophthalmoscope. BrF Ophthalmol 1992;76:470-4.

6 Jaffe GJ, Alvarado JA, Juster RP. Age-related changes of the normal visual field. Arch Ophthalmol 1986;104:1021-5.

7 Johnson CA, Adams AJ, Lewis RA. Evidence for a neural basis of age-related visual field loss in normal observers. Invest Ophthalmol Vis Sci 1989;30:2056-64.

8 Lynn JR, Felloman RL, Starita RJ. Principles of perimetry In: Ritch R, Shields MB, Krupin J, eds. The glaucomas. 2nd ed. St Louis: CV Mosby, 1996:491-537.

9 Caprioli J, Miller JM. Optic disc rim area is related to disc size in normal subjects. Arch Ophthalmol 1987;105:1683-5.

10 Britton RF, Drance SM, Schulzer M, Douglas GR, Mawson Britton RF, Drance SM, Schulzer M, Douglas GR, Mawson
DK. The area of the neuroretinal rim of the optic nerve in DK. The area of the neuroretinal rim of the optic

11 Sommer A, Pollack I, Maumenee AE. Optic disc parameters and onset of glaucomatous field loss. Arch Ophthalmol 1979;97:1444-54.

12 Funk J. Early detection of glaucoma by longitudinal monitoring of the optic disc structure. Graefes Arch Clin Exp Ophthalmol 1991;229:57-61.

13 Zeyen TG, Caprioli J. Progression of disc and field damage in early glaucoma. Arch Ophthalmol 1993;111:62-5.

14 Bengtsson B. The variation and covariation of cup and disc diameters. Acta Ophthalmol 1976;54:804-18.

15 Rohrschneider K, Burk ROW, Kruse FE, Volcker HE. Reproducibility of the optic nerve head topography with a new laser tomographic scanning device. Ophthalmology new laser tomograpt

16 Quigly HA, Brown AE, Morrison JD, Drance SM. The size and shape of the optic disc in normal human eyes. Arch Ophthalmol 1990;108:51-7. 
17 Nicolela MT, Drance SM. Various glaucomatous optic nerve appearances. Ophthalmology 1996;103:640-9.

18 Schwartz JT, Reuling FH, Garrison RJ. Acquired cupping of the optic nerve head in normotensive eyes. Br $\mathcal{F}$ Ophthalmo 1975;59:216-22

19 Bengtsson B. The alteration and asymmetry of cup and disc diameters. Acta Ophthalmol 1980;58:726-32.

20 Carpel EF, Engstrom PF. The normal cup-disc ratio. Am $\mathcal{F}$ Ophthalmol 1981;91:588-97.

21 Balazsi AG, Rootman J, Drance SM, Schulzer M, Douglas GR. The effect of age on the nerve fiber population of the human optic nerve. Am f Ophthalmol 1984;97:760-6.

22 Tsai CS, Ritch R, Shin DH, Wan JY, Chi T. Age-related decline of disc rim area in visually normal subjects. Ophthalmology 1992;99:29-35.

23 Jonas JB, Gusek GC, Naumann GOH. Optic disc cup and neuroretinal rim size configuration and correlations in normal eyes. Invest Ophthalmol Vis Sci 1988;29:1151-8.

24 Funk J, Dieringer J, Grehn F. Correlation between neuroretinal rim area and age in normal subjects. Graefes neuroretinal rim area and age in normal sub
25 Johnson BM, Miao M, Sadun AA. Age-related decline of human optic nerve axon populations. Age 1987;10:5-9.

6 Repka MX, Quigley HA. The effect of age on normal human optic nerve fiber number and diameter. Ophthalmology 1989;96:26-32.

27 Varma R, Tielsch JM, Quigley HA, Hilton SC, Datz J, Spath JL, et al. Race, age, gender, and refractive error related differences in the normal optic disc. Arch Ophthalmol 1994; 112:1068-76.

28 Mikelberg FS, Drance SM, Schulzer M, Ridegiligne HM, Weis MM. The normal human optic nerve: axon count and axon diameter distribution. Ophthalmology 1989;96:13258.

29 Mikelberg FS, Yidegiligne HM, White VA, Schulzer M. Relation between optic nerve axon number and axon diameter to scleral canal area. Ophthalmology 1991;98:603 .

30 Jonas JB, Schmidt AM, Muller-Bergh JA, ScholtzerSchrehardt UM, Naumann GOH. Human optic nerve fiber count and optic disc size. Invest Ophthalmol Vis $S c i$ 1992;33:2012-8. 